Table 1.

\begin{tabular}{|c|c|c|c|}
\hline & $\begin{array}{l}\text { axSpA without IBD } \\
(\mathrm{n}=829)\end{array}$ & $\begin{array}{l}\text { axSpA with IBD } \\
(n=57)\end{array}$ & $\mathbf{p}$ \\
\hline Men/Women, $\mathrm{n}$ & $272 / 557$ & $15 / 42$ & 0.33 \\
\hline Mean age (years) $\pm S D$ at the time of study & $49 \pm 13$ & $49 \pm 10$ & 0.99 \\
\hline AS/nr-AxSpa & $656 / 173$ & $45 / 12$ & 0.97 \\
\hline \multicolumn{4}{|l|}{ History of CV risk factors } \\
\hline $\begin{array}{l}\text { Current smoker } \\
\text { Obesitty }\end{array}$ & $285(34)$ & $12(21)$ & 0.045 \\
\hline Dyslipemia & $280(34)$ & $16(28)$ & 0.42 \\
\hline Hypertension & $223(27)$ & $16(28)$ & 0.79 \\
\hline Diabetes Mellitus & $60(7)$ & $4(7)$ & 0.99 \\
\hline Chronic Kidney Disease & $20(2)$ & $2(4)$ & 0.65 \\
\hline History of cardiovascular events, $n$ (\%) & $40(5)$ & $2(4)$ & 0.99 \\
\hline \multicolumn{4}{|l|}{ Structural damage at the time of study } \\
\hline Presence of syndesmophytes, n (\%) & 307 (37\%) & $23(49 \%)$ & 0.66 \\
\hline mSASSS & $5(1-15)$ & $6(3-23)$ & 0.64 \\
\hline Severe sacroiliitis (grade 3,4), n (\%) & $436(53)$ & $34(60)$ & 0.42 \\
\hline \multicolumn{4}{|l|}{ CV data at the time of study } \\
\hline Carotid plaques & $261(31)$ & $21(37)$ & 0.45 \\
\hline IMT (mm) & $645 \pm 147$ & $636 \pm 112$ & 0.64 \\
\hline IMT > $=0.9 \mathrm{~mm}$ & $46(6)$ & $0(0)$ & 0.066 \\
\hline
\end{tabular}

Abbreviations: $\mathrm{AS}=$ ankylosing spondylitis. $\mathrm{AxSpA}=$ axial spondylitis. $\mathrm{CV}=$ cardiovascular. IBD $=$ Inflammatory bowel disease. IMT = intima-media wall thickness. $\mathrm{Nr}$-axSpA = no-radiographic axial spondylitis.

Disclosure of Interests: None declared

DOI: 10.1136/annrheumdis-2021-eular.3802

\section{POS1408 REPRODUCIBILITY OF A NEW AUTOMATIC SYSTEM (CAPILLARY.IO) IN THE ANALYSIS OF NAILFOLD CAPILLAROSCOPY IMAGES}

B. Gracia Tello ${ }^{1,2}$, E. Ramos ${ }^{3}$, C. P. Simeón-Aznar ${ }^{4}$, V. Fonollosa Pla ${ }^{4}$, A. GuillénDel-Castillo ${ }^{4}$, A. Selva-O'callaghan ${ }^{4}$, L. Sáez-Comet ${ }^{5}$, E. Martínez Robles ${ }^{6}$, J. J. Rios ${ }^{6}$, G. Espinosa ${ }^{7}$, J. A. Todolí Parra ${ }^{8}$, J. L. Callejas-Rubio ${ }^{9}$, N. Ortego ${ }^{9}$, B. Marí-Alfonso ${ }^{10}$, M. Freire ${ }^{11}$, P. Fanlo ${ }^{12} .{ }^{1}$ Hospital Clínico Universitario Lozano Blesa, Zaragoza. Spain, Internal Medicine, Zaragoza, Spain; ${ }^{2}$ Zaragoza, Instituto de investigación Sanitaria de Aragón (ISSA), Zaragoza, Spain; ${ }^{3}$ Zaragoza, Computer Science Graduate by University of Zaragoza, Zaragoza, Spain; ${ }^{4}$ Hospital Universitari Vall d'Hebron, Unit of Autoimmune Diseases, Department of Internal Medicine, Barcelona, Spain; ${ }^{5}$ Hospital Universitario Miguel Servet, Department of Internal Medicine, Zaragoza, Spain; ${ }^{6}$ Hospital General Universitario La Paz, Department of Internal Medicine, Madrid, Spain ${ }^{7}$ Hospital Clínic, Department of Internal Medicine, Unit of Autoimmune Diseases, Barcelona, Spain; ${ }^{8} \mathrm{Hospital}$ La Fe, Department of Internal Medicine, Valencia, Spain; ${ }^{\circ}$ Hospital Universitario Virgen de las Nieves, Unit of Autoimmune Diseases, Department of Internal Medicine, Granada, Spain; ${ }^{10} \mathrm{Hospital}$ Universitario Parc Taulí, Department of Internal Medicine, Sabadell, Spain; ${ }^{11}$ Complejo Hospitalario Universitario de Santiago, Department of Internal Medicine, Santiago de Compostela, Spain; ${ }^{12}$ Complejo Hospitalario de Navarra, Pamplona, Department of Internal Medicine, Pamplona, Spain

Background: Nailfold Capillaroscopy is a simple, inexpensive and non-invasive technique that allows microvascular damage to be observed, gaining recent importance in the diagnosis, monitoring and prognosis of many diseases with microangiopathy. However, the variability in the results interpretation has led to the development of new computerized systems that allow the automatic analysis of capillaroscopic images.

Objectives: to compare the degree of agreement between the automatic system Capillary.io and a gold standard obtained from the agreement of 9 expert capillaroscopists and to know the degree of the interobserver reliability To demonstrate the validity of the system to detect normal and enlarged capillaries, hemorrhages, megacapillaries, ramifications and tortuosities.

Methods: a cross-sectional study was performed in which 300 random and anonymous nailfold capillaroscopic images (1165 capillaries) were analyzed by 9 experienced observers. The degree of interobserver agreement was calculated from the 5 users. Likewise, the system performed an automatic assessment of the images and their agreement with the gold standard was calculated (interobserver agreement greater than 5, 6, 7, 8 and 9 successively). The validity of the program for each variable was also analyzed using sensitivity and specificity, positive and negative predictive values, and likelihood ratios, as well as their degree of agreement using the weighted kappa statistic $(95 \% \mathrm{Cl}, \mathrm{p}<0.05)$. The programs used for statistical calculations were SPSS 22.0 and EPIDAT 3.0 .

Results: the degree of interobserver agreement was $76.5 \%$ for the agreement of 5 or more observers, progressively decreasing to $15.4 \%$ for the 9 observers. Capillary.io obtained higher levels of agreement, reaching $97.7 \%$ for the 9 observers. Statistically significant results were obtained in the automated detection of all the morphological alterations analyzed Capillary.io presented a sensitivity (S) of $79.82 \%$ and a specificity (E) of $82 \%$ in the recognition of normal capillaries. The automatized system was able to recognize enlarged capillaries with a sensitivity of $86.97 \%$ and a specificity of $81.38 \%$. Megacapillaries were detected with $89.41 \%$ sensitivity and $78.75 \%$ specificity. Similarly, the system was able to detect tortuosities (S $66.94 \%$; E $67.71 \%$ ), ramifications (S 54.34\%; E 58.61\%) and hemorrhages (S 71.36; E 73.97\%)

Conclusion: Capillary.io demonstrated a high degree of agreement with the gold standard, stronger with greater consensus among observers. It was able to detect with great sensitivity and specificity hemorrhages and megacapillaries, very relevant alterations in microangiopathies.

\section{REFERENCES:}

[1] Roldán LMC, Franco CJV, Navas MAM. Capillaroscopy in systemic sclerosis: A narrative literature review. Rev Colomb Reumatol; 2016; 23: 250-8.

[2] Ingegnoli F, Gualtierotti R, Lubatti C, Bertolazzi C, Gutierrez M, Boracchi P, et al. Nailfold capillary patterns in healthy subjects: $A$ real issue in capillaroscopy. Microvasc Res. 2013;90:90-5.

[3] Cutolo M, Pizzorni C, Secchi ME, Sulli A. Capillaroscopy. Best Pract Res Clin Rheumatol. 2008; 22:1093-108.

[4] Tavakol ME, Fatemi A, Karbalaie A, Emrani Z, Erlandsson BE. Nailfold Capillaroscopy in Rheumatic Diseases: Which Parameters Should Be Evaluated? BioMed Res Int. 2015; 2015: 974530.

[5] Smith V, Herrick AL, Ingegnoli F, Damjanov N, De Angelis R, Denton CP, et al. Standardisation of nailfold capillaroscopy for the assessment of patients with Raynaud's phenomenon and systemic sclerosis. Autoimmunity Reviews. 2020; 19: 102458.

Disclosure of Interests: Borja Gracia Tello Shareholder of: Co-founder and shareholder of Capillary.io., Eduardo Ramos Shareholder of: Co-founder and shareholder of Capillary.io., Carmen Pilar Simeón-Aznar: None declared, Vicent Fonollosa Pla: None declared, Alfredo Guillén-Del-Castillo: None declared, Albert Selva-O'Callaghan: None declared, Luis Sáez-Comet: None declared, Elena Martínez Robles: None declared, Juan José Rios: None declared, Gerard Espinosa: None declared, Jose Antonio Todolí Parra: None declared, Jose Luis Callejas-Rubio: None declared, Norberto Ortego: None declared, Begoña Marí-Alfonso: None declared, Mayka Freire: None declared, Patricia Fanlo: None declared

DOI: 10.1136/annrheumdis-2021-eular.4063

POS1409

\section{AUTOMATED DETECTION OF SCLERODERMIFORM} PATTERNS USING CAPILLARY.IO

E. Ramos ${ }^{1}$, A. Guillén-Del-Castillo², C. P. Simeón-Aznar ${ }^{2}$, B. Gracia Tello ${ }^{3,4}$ V. Fonollosa $\mathrm{Pla}^{2}$, A. Selva-O'callaghan ${ }^{2}$, L. Sáez-Comet ${ }^{5}$, E. Martínez Robles $^{6}$, J. J. Rios ${ }^{6}$, G. Espinosa ${ }^{7}$, J. A. Todolí Parra ${ }^{8}$, J. L. Callejas-Rubio ${ }^{9}$, N. Ortego ${ }^{9}$, B. Marí-Alfonso ${ }^{10}$, M. Freire ${ }^{11}$, P. Fanlo ${ }^{12}$. ${ }^{1}$ Zaragoza, Computer Science Graduate by University of Zaragoza, Zaragoza, Spain; ${ }^{2}$ Hospital Universitario Vall d'Hebron, Unit of Autoimmune Diseases, Department of Internal Medicine, Barcelona, Spain; ${ }^{3}$ Hospital Clinico Universitario Lozano Blesa, Department of Internal Medicine, Zaragoza, Spain; ${ }^{4}$ Zaragoza, Instituto de Investigación Sanitaria de Aragón (ISSA), Zaragoza, Spain; ${ }^{5}$ Hospital Universitario Miguel Servet, Department of Internal Medicine, Zaragoza, Spain; ${ }^{6}$ Hospital General Universitario La Paz, Department of Internal Medicine, Madrid, Spain; ${ }^{7}$ Hospital Clínic, Department of Internal Medicine, Unit of Autoimmune Diseases, Barcelona, Spain; ${ }^{8} \mathrm{Hospital} L \mathrm{La} F$, Department of Internal Medicine, Valencia, Spain; ${ }^{9}$ Hospital Universitario Virgen de las Nieves, Unit of Autoimmune Diseases, Department of Internal Medicine, Granada, Spain; ${ }^{10}$ Hospital Universitario Parc Taul, Department of Internal Medicine, Sabadell, Spain; ${ }^{11}$ Complejo Hospitalario Universitario de Santiago, Department of Internal Medicine, Santiago de Compostela, Spain; ${ }^{12}$ Complejo Hospitalario de Navarra, Department of Internal Medicine, Pamplona, Spain

Background: A nailfold capillaroscopy procedure is a non-invasive, low-cost and well-established examination that can be used to diagnose several rheumatic autoimmune diseases and support the necessary follow-up of patients While the clinical implications of the technique are known, a rigorous and in-depth examination of nailfold capillaries remains as one of the major challenges to produce new advances in research and diagnosis, due to practical limitations for analysing the whole nailfold area of each patient. The difference between the different patterns established by Maricq and Cutolo makes it possible to predict the evolution that the patient will present. We introduce Capillary.io, an automatic image reading system able to recognize capillaries in images obtained with any microscope, generate automatic measurements of each capillary and take advantage of this information to report capillary morphology and patterns.

Objectives: to determine the ability to detect active and early scerodermiform patterns of Capillary.io. 